\title{
Retrospective Analysis of Female Patients Admitted to Hospital Due to Suicide Attempts
}

\author{
Hüseyin Kafadar ${ }^{1 *}$, İrfan Aydın ${ }^{2}$ \\ ${ }^{1}$ Adiyaman Univesity, Depatment of Forensic Medicine, Adlyaman, Turkey \\ ${ }^{2}$ Adlyaman Univesity, Depatment of Emergence Medicine, Adlyaman, Turkey
}

*Corresponding Author: Hüseyin Kafadar, Adlyaman Univesity, Depatment of Forensic Medicine, Adlyaman,Turkey, Email: dr.hkafadar@gmail.com

\begin{abstract}
Introduction: In this study, we aimed to is a retrospective review of female patients who were admitted to hospital after having attempted suicide

Material and Method: The files of female cases showing suicidal behaviour(suicide attempts and/orselfinflicted injuries) between 01.09.2014 and 30.09.2017 in the Adiyaman University,Training and Research Hospital, were investigated retrospectively. Suicide methods, distribution of suicide attempt cases throughout the seasons, the effect of gender on the time of application to the hospital and differences between age groups were examined.
\end{abstract}

Result: Of 534 of cases, 409 (74.9\%) of cases were female and 125 (25.41\%) were male. The mean age of the patients studiedwas $34.39 \pm 9.4$. Analysed by age group, the most suicide attempts (N: 250, 61.12\%) occurredin the group aged 15-24. This value was judged statistically significant ( $p<0.05)$. Examined by educational status, the greatest number of cases $(N: 169,41.34 \%)$ were primary school graduates. Family issues were the foremost cause of triggering (102 cases, 24.94\%).

The most commonsuicide attempt method(386 cases, 94.37\%) determined to be ingestion of drugs or toxic substances.

Conclusion: Feelings of hopelessness and a lack of self-worth or self-esteem, along with an inability to cope with the challenges of life, play an important role in the ideation of suicide. Careful follow-up of the events in the risk group and knowledge of the risk factors may reduce suicide attempts.

We consider that this study will contribute to the literature because it examines the factors that cause suicide attempts and suicidal thoughts in females.

Keywords: Suicide, self-inflicted, female suicide, suicide attempt, forensic medicine, emergency medicine

\section{INTRODUCTION}

Suicide has been described in various forms in multiplestudies, and the World Health Organization has defined it as "self-destructive for the purpose of one's self and for various lethal purposes"[1-3]. According to Durcheim,"Every death that is brought directly or indirectly to the cause of the negative action taken by the victim of the incident knowing that it will bring death is called suicide"[4-6].

Suicidal action involves a complex process ranging from the planning of suicidal ideation to the attempted suicide and finally the completion of the action [7-9].For this reason, it is possible to divide the act of suicide intotwo parts. The first is the suicide attempt, and the second iscompleted or real suicide $[1,4,7]$.

It is known that the formation of suicidal ideation is influenced by psychological, biological and sociocultural factors $[4,7,8]$.Social failure and economic and psychological problems can also trigger suicidal thoughts[1,3,9].

Suicide action can be seen in individuals with serious mental and physical discomfort, as well as in a large population of society with no apparent problems or illnesses, that is, in otherwise normal individuals who cannot produce solutions to difficult life conditions and who therefore feel hopeless $[8,10]$. 
It is estimated that more than 800,000 people commit suicide each year and more and more suicide attempts have resulted in death, suggesting that a larger than ever number ofsubjects are more determined to carry out this action. Since suicide-related deaths are preventable deaths and are seen mostly in the young population, it is once again increasing inimportance [3,11].In many countries, it has been acknowledged that suicidal behaviour has increased in recent years and has therefore become a universal public health problem [11].

With a greater understanding the pathophysiology and other underlying causes of the process from the thought of suicide to the realization of the action, a new era has begun in terms ofmeasures that mustbe takento combat this growing problem [3-5].Analysed by gender, we find differences in suicidal behaviour according to age groups, cultural level, and education levels, from country to country and even from region to region $[3,4,11]$. Measures that are more effective can be taken if we understand the role of gender in suicide ideation and action, the underlying biological parameters related to sex, psychological stress factors, the relationship between age groups, and the most frequently used methods within each age group [3,11-13].

In conclusion, we believe that this study will contribute to the literature because it studies the factors that cause suicide attempts and suicidal thoughts in females.

\section{MATERIALS AND METHODS}

We examined the files of female suicide and/or suicide attempt cases Adiyaman University, Training and Research Hospital between 01.09.2014 and 30.09.2017. The female cases evaluated in this study were assessed and analysis was conducted that considered the marital status, education, occupation, area of the suicide attempt, suicide reason, suicide method, tools used for the suicide, injury area and time of the suicide attempt in each case.Age groups includedtheteen-to-young adultgroup (15-24 years), young adult age group (25-35 years), adult age group (36-49 years) and middle-aged age group (50-64 years). Persons over the age of 64 were consideredto be in the advanced age group.In this study, the most commonly used suicide method, the underlying causes, the causes of suicide-induced stress, and the distribution of cases in terms of age groups were examined. Moreover, we also assessed whether there was a difference in the distribution of the cases according to the seasons, the months, and the time of day at which the patient was admittedto the hospital.

As a criterionfor inclusion in the study, patient file information applied to the hospital of cases using any method for suicide was examined. Exclusionary criteria included the patient not being female, the patient having accidentally taken drugs, or having committed suicide without actual suicidal intent.Females under 15 years of age were not included in the study, as they were admitted to the child emergency unit.

In the study, categorical variables were given as frequency and percentage, descriptive statistics and continuous variables as mean \pm standard deviation.

Categorical variables were grouped, percentages calculated, and Pearson's chi-square or Fisher's exact test was used to compare frequencies according to suitability. All statistical analyses were performed using the SPSS 22 program, andP $<0.05$ was accepted as a statistically significant value. The relationship or differencesamongthe groups were statistically explained.

\subsection{Findıngs}

In this study, female cases of suicide attemptsand completedsuicides between 01.09.2014 and 30.09.2017 were investigated. It was determined that 534 suicide cases were admitted to the hospital between the dates noted, of which 409 cases were women $(74.59 \%)$ and 125 cases were men $(25.41 \%)$. Female cases were included in the study. The mean age of the cases was $34.39 \pm 9.4$. In the study, the 125 male cases $(25.41 \%)$ and suicidesresulting fromaccidental medication and self-injurywere excluded from the study.

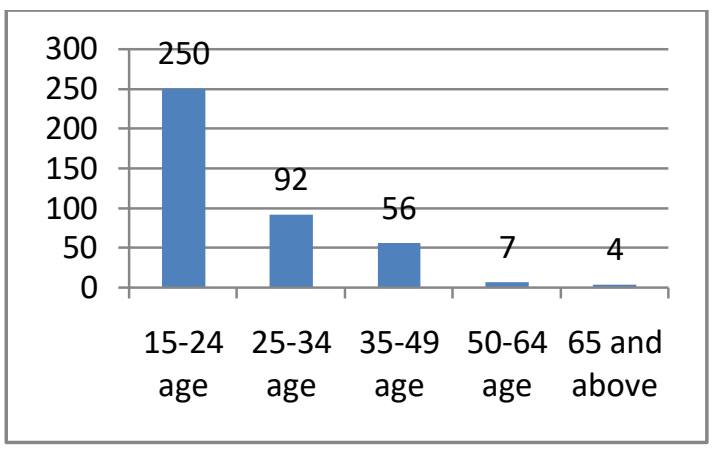

Graph 1. Distribution of cases according to age groups. (x: age groups, $\boldsymbol{y}$ : case numbers)

When cases were examined according to age groups, the most cases $(250,61.12 \%)$ werefound with in the15-24 age group and this value was 
found to be statistically significant $(\mathrm{p}<0.05)$. There were $92(22.49 \%)$ cases in the young adult age group (25-35 years). Fifty-six $(13.69 \%)$ cases were foundin the adult age group (36-49 years). The middle age group (5064 years) includedseven cases $(1.71 \%)$ and only four $(0.97 \%)$ suicide cases were in the group over 65 years (Graph 1).

When the cases wereevaluated according to their marital status, most suicide cases (199 cases, or $48.72 \%$ ) were single. The second largest group was married women and then widowed persons (Table 1).

Table 1. Distribution of cases according to marital status

\begin{tabular}{|l|l|l|}
\hline \multicolumn{1}{|c|}{ Marital status } & \multicolumn{1}{c|}{ N } & \multicolumn{1}{c|}{ \% } \\
\hline Married & 171 & 41.85 \\
\hline Single & 199 & 48.72 \\
\hline Widow & 26 & 6.59 \\
\hline Engaged & 12 & 2.58 \\
\hline Living Separately & 1 & 0.26 \\
\hline Total & $\mathbf{4 0 9}$ & $\mathbf{1 0 0}$ \\
\hline
\end{tabular}

When the cases were analysedaccording to educational status, it was notedthat of 169 cases $(41.34 \%)$ were primary school graduates, while secondary school education was the second group. 23 of the cases were determined to be illiterate (Table 2).

Table 2. Distribution of cases according to educational status

\begin{tabular}{|l|l|l|}
\hline \multicolumn{1}{|c|}{ Education status } & \multicolumn{1}{c|}{ N } & \multicolumn{1}{c|}{$\%$} \\
\hline Illiterate & 23 & 5.64 \\
\hline Primary education & 169 & 41.34 \\
\hline Secondary education & 136 & 33.24 \\
\hline University & 65 & 15.87 \\
\hline Unknown & 16 & 3.91 \\
\hline Total & 409 & 100 \\
\hline
\end{tabular}

The largest group of patient's werehousewives, with 170 cases $(41.56 \%)(\mathrm{p}<0.05)$.Students $(86$, or $21.03 \%$ ) were the second largest group (Graph 2).

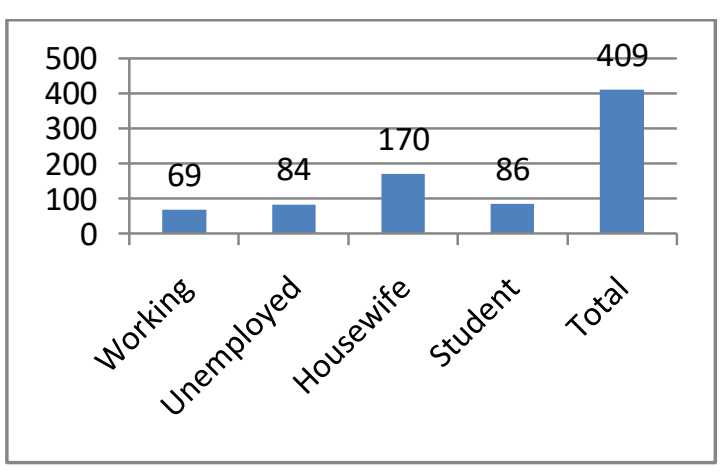

Graph 2. Distribution of cases according to employment status
In terms of employment, the largest group consisted of not qualified workers with 43 cases $(62.32 \%)$, most of themin thetextile sector and in secretarial services. Office workers constituted 18 cases $(26.08 \%)$ of the working group. The largest groupof employed patients were teachers with five cases.Nurses constitutedfour cases, bank employees three, artisans three and the not qualified officer's three cases. It was determined that seven of the cases in the unemployed group $(8.33 \%)$ were prisoner.

When the cases are examined in terms of the methods used in the suicide attempts, of the most common method (386, or $94.37 \%$ ) was the ingestion of drugs or toxic substances and this ratio was found to be statistically significant ( $p$ $<0.05$ ). It was determined that 367 of these cases had ingested multiple drugs, while nine ingested a corrosive substance, five had swallowed liquid soap or shampoo, two had utlised insecticide, two overdosed on alcohol and two admitting bonsai. (Bonsai is a cheap synthetic, addictive drug.) (Graph 3).

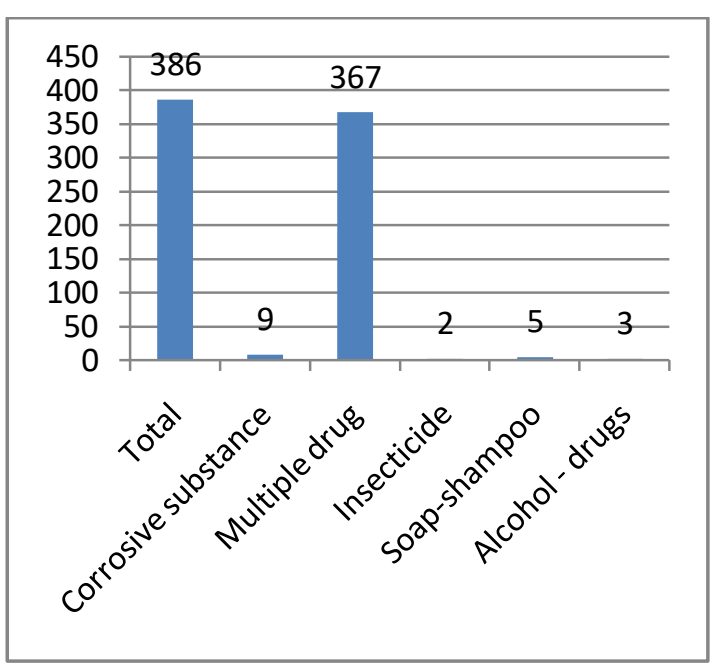

Graph 3. Distribution of cases according to drugtoxic substance use

There were seven cases in which the patientattempted or completed suicide by using a sharp and penetrating object, one in which a firearm was used, nine were high jumper cases and there was one unknown case. Among the cases in which the suicide was prevented, three used sharp and penetrating objects. After ward, those patients were admitted to hospital.

Only one case at the age of 15 was suicide attempting method by firearm. It was learned she had tried to commit suicide twice before. And it was found out that there was a discussion with her boyfriend among the triggering causes. 
Neither alcohol-drug use norpsychiatric illnesses were detected.

It was determinedthat family reasons were the major cause of suicide or suicide attempts, with 102 cases $(24.94 \%)$. Suicide attempt due to problems with the opposite sex was found to be the second leading cause, with 50 cases $(12.23 \%)$. Other triggering factors included mental illness, marital problems with the spouse, parental conflict, problems with children, domestic violence, loneliness, communication problems, economic issues, sickness, death or suffering loss, test anxiety, school problems, harassment, sexual problems, work, homelessness. No cases of suicide attempt were determined to be causedby rape or alcoholsubstance addiction (Graph 4).

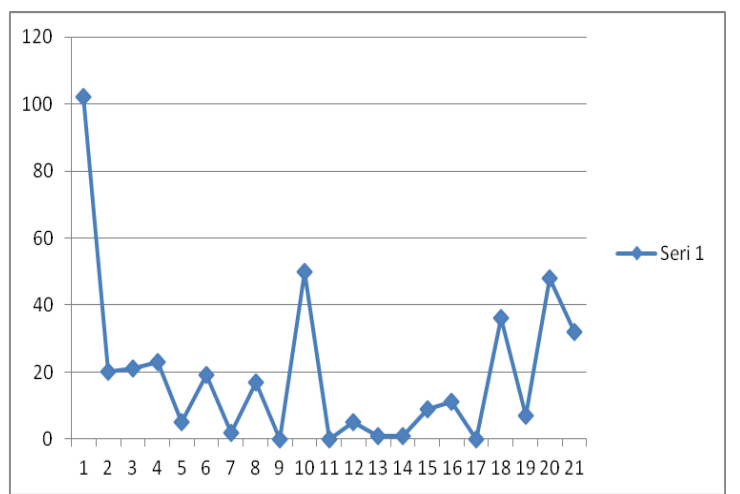

Graph 4. Distribution of cases according to causes of suicide

Family problems (1), Domestic violence (2) Parental Conflict (4), Children (3), Death or suffering loss (5), Loneliness (6), Harassment (7), Communication problems (8), Rape (10), Sexual problems (11), School (12), Work (13), Homelessness (14), Economics (15), Examination Anxiety (16), Alcohol and substance addiction (17), Marriage problems (18), 20) Discussed with his wife (21)

There were five suicides by hanging, seven via the use of a cutting and penetrating object, one by firearm, high jumpers were nine, and one cause was unknown.In the three cases in whichhanging was used, all threewere prevented from committing suicide; in one case the material being used in the hanging attempt broke or tore. The hanging material was removedat an early stage in one case, and the patient was then brought to the hospital. The 27year-old married women, who had twice previously attempted suicide, was noticed at an early stage, andwas brought to the hospital within 25 minutes.It was learned from patient card that the patient's pulse and breathing were superficial and who had been admitted to the hospital, with anti-enema treatment started and then five days later she died (Figure 1).
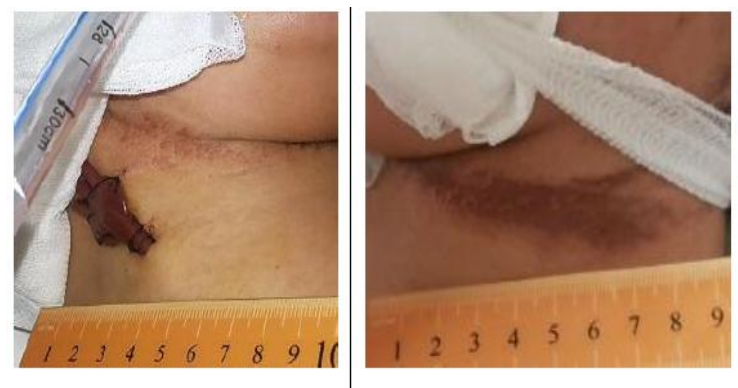

Figure 1. The ligature mark is seen on the patient's neck

When the distribution of suicide attempt cases was evaluated according to the month, most (63 cases, or $15.40 \%$ ) were seen to have occurred in July. The fewest(15 cases, or $3.66 \%$ ) were seen in February. The difference was found to be statistically significant $(\mathrm{p}<0.000184)$. When suicide attempts were analysed by season, 184 $(44.50 \%)$ were in summer, while and 72 $(17.60 \%)$ of the cases occurred inwinter.The difference was determined to be statistically significant $(\mathrm{p}<0,023)$ (Graph 5).

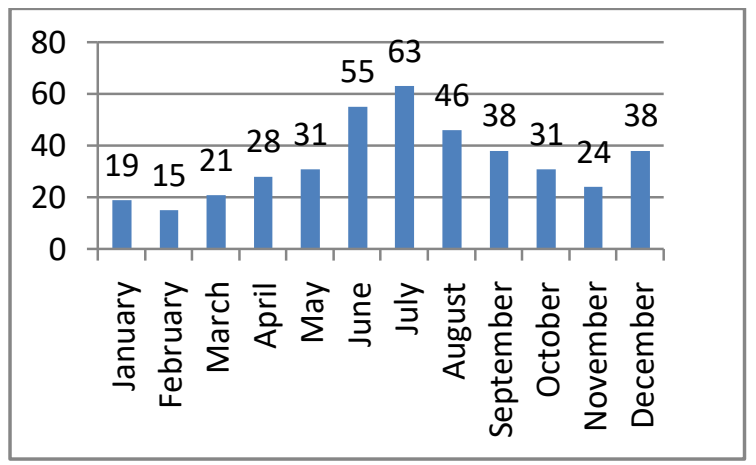

Graph 5. Monthly distribution of suicide cases

It was determined that $254(62,10 \%)$ of the attempted suicide hours were between 18.00 and 05.00 hours. It was found that the time to apply to the hospital from the suicide attempt was at the earliest 25 minutes, at the latest 3 hours 15 minutes.

Of the patients who had been treated for psychiatric diseases, a total of 78 cases, it was found that 59 patients suffered from depression, eighthad anxiety, three had schizophrenia, one had obsessive-compulsive disorder (OCD), and 10 patients had other diagnoses. (Graph 6).

Of 254 cases, mostattempts $(62.10 \%)$ occurred between 18,00 and 05,00 hours. The shortest trip to the hospital after a suicide attempt was 25 minutes, while the slowest was 3 hours and 15 minutes.

Seventy-two of the 254 cases (17.60\%) had previously attempted suicide, six were drug addicts, and three were using alcohol. 


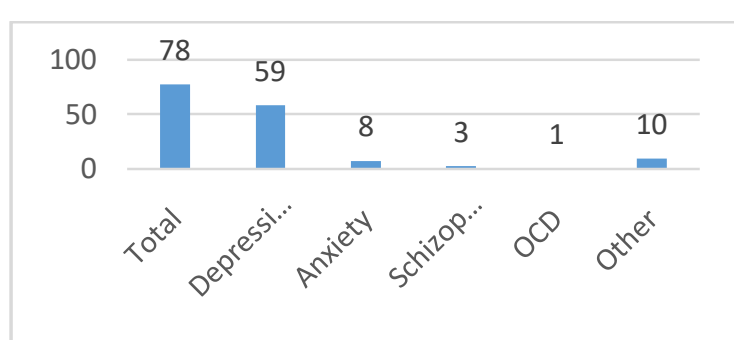

Graph 6. Distribution of psychiatric disorders in suicide attempt cases.

OCD: Obsessive Compulsive Disorder

\section{DISCUSSION}

According to WHO-2016 data, one million deaths suicide deaths worldwide are reportedper year [10].Other studies have noted that suiciderelated deaths have been reported to be among the top ten causes of deaths worldwide [15].This data demonstrates the importance of understandingthe causesof suicide attempts.

Various risk factors have been suggestedas causesin the conversion of suicide ideation and then the act of suicide. One of them is the gender factor [10-13]. According to WHO-2016 data, the rate of attempted suicide in women is higher than in men [10].A study by Prasko et al. reveals that women are three times more likely to commit suicide than men.It has been reported that women often postpone their suicide attempts in order to reflect on their suffering or "call for help." However, men may also postpone suicide attempts until helplessness and hopelessness become unbearable [11]. Similarly, studies of groups in different provinces of Turkey-Elazığ (19 years old), Adana (0-18 years), Isparta, Sivas (13-19 years), Istanbul (11-20 years), Istanbul (19 years old), Forensic Medicine Institution (15-19 years) studies revealed that female cases attempting suicide were more frequent than male cases [4,12-17].Furthermore, Jeffrey Bridge et al. (in studies in China) reported that female suicide rates were also higher there than in men (18).On contrast, Prasko and et al. (in 2010) have revealed that the commit suicide rate in men is four times greater than that of women [11].

Age is also an important factor insuicide risk. Although there are differences between age groups according to culture, belief, education level and socio-economic level, most studies who that suicide attempts and completed suicides were more common in the 15-24 age group [1-8].Suicides and suicide attempts areleast frequently seenin the childhood age
group.This may be because children tend not to understand the concept of death before reaching a certain age, and therefore the rate of suicide is low. However, with the beginning of adolescence there is an increase in suicide rates [4,19-22].

Not surprisingly, then, in the present study, it was determined that suicide attempts in 250 cases $(61.12 \%)$ were seen most frequently in the 15-24 age group.

It has been suggested that the vast majority (approximately $60 \%$ ) of those attempting suicide may suffer from psychiatric illness or mental confusion [11,22-26].It is pointed out that there may be a higher risk for suicide attempts in cases with depression, depressive neurosis, psychosis, agitation, severe anxiety disorder, posttraumatic stress disorder (PTSD), schizophrenia, unipolar and bipolar affective disorders, hypochondriasis and borderline personality disorder [20-23,25-27].Roy (1983) reported that $118(24.6 \%)$ of 243 suicide stories in the family had suicide attempts (almost half, 48.6\%), 137 (56.4\%) depressive disorders and $34 \%$ recurrent affective disorder [26].Again, Roy (2003) reported that suicide risk in patients with psychiatric disordersmay increase 3 to twelvetimes more than those without a history of psychiatric illness [27].In astudy conducted by Mermi et al., $42 \%$ of patients attempting to commit suicide were found to be suffering from a psychiatric illness [28].The most common psychiatric disorders associated with suicide are depression and associated mood disorders. However, depression is a vague term that coversa wide spectrum of mild to severe, transient, and permanent forms of illness and disease, and suicide risk varies significantly from one form of depression to another [2731].In otherstudies, it has been reported that about $15 \%$ of individuals with mood disorders and about $10 \%$ of psychosis patients end their lives by suicide [11,27-32].Other studies foundthat depression may occur in 50\% of cases during suicide, whilemore than $90 \%$ of completed suicides are diagnosed as having some severe form of mental illness $[11,32,33]$.All these data show that suicidal behaviouris often caused by a combination of susceptibility and associated multiple risk factors that combine to encourage the development of suicidal ideation [31-35].

In the present study, most of the cases with psychiatric diagnosis $(67.04 \%, 59$ cases $)$ were 
diagnosed with depression. This data was found to be in accordance with the literature. Anxiety was found in $9.09 \%$ of the cases, schizophrenia in $3.40 \%$, and obsessive-compulsive disorder in one patient. Ten cases received other diagnoses.However, it was found that 88 $(21.52 \%)$ of the cases in the studyinvolvea psychiatric diagnosis. This data is not coherent with the literature, possibly because $62 \%$ of the cases involve patientsless than 25 years of age and those may not yet have been diagnosed as having a psychiatric disorder.

Family reasons are another important risk factor in suicide attempts. For example, separate living or divorced parents, counter-gender conflicts and psychopathological conditions in the parents also increase the risk of suicide.Disagreements duringthe divorce process can trigger suicide attempts by negatively affecting people, including children[35-38]. However, it has beendemonstrated that adolescents are most affected byfamily problems [2-6, 39].Risk factors such as death or suffering severe loss, school failure, and lack of communication may also be associated with increased suicide attempts in adolescents [18,40,41].A high rate of suicide attempts and suicide in adolescents have been designated an important public health problem by the World Health Organization [26].

In this study, the most common risk (102 cases, $24.94 \%$ ) of suicide was associated with family issues. The second most common cause of the trigger (50.2\%), was attributed to problems with the opposite sex. Other factors were marital problems, lack of communication with parents, parental conflict, children's problems, domestic violence, communication problems and loneliness, test anxiety, suffering death or severe loss, school problems. However, it was determined in this study that mothers who were not mentioned in previous studies were attempting suicide because they could not cope with their children $(5,38 \%)$ in this study.

Intoxication is the most common means of attempting suicide noted in the literature [4045].In this study, intoxication was also determined to be the most common cause, with 386 cases $(94.37 \%)$.

Suicide methods vary in different cultures $[3,5,7]$.Hanging is the most commonly used method in Asian cultures and developing countries $[4,10,41-45]$. In a study conducted in Israel on all age groups and two different studies by the Forensic Medicine Institute (in the 15-19 age group and under 19 age),however, firearms were found to bethe most common methodof attempting suicide $[16,44]$.

In our study, high jump was $2.20 \%$, cutting instrument was $1.71 \%$, hangingmethod was $1.22 \%$ and onecase of a suicide attempt with a firearm was detected.Other data in the study determined that $44.50 \%$ of cases occurred in summer, $15.40 \%$ of themin July. The differenceswere statistically meaning $(\mathrm{p}<0,05)$. It was determined that in $254(6210 \%)$, the attempted suicide occurred between 1800 and 0500 hours. This can be interpreted as a "timeout opportunity"during whichvictims were left alone after working hours and spent time thinking about suicide. Another important piece of datais the time it takes to reach the hospital after an attempted suicide. The cases most quicklybrought to the hospital took 25 minutes, while the longest trip took 3 hours and 15 minutes. On the average, it took patients 1 hour and 46 minutes to reach the hospital.

In the end, stress factors such as hopelessness and a sense of worthlessness in individuals, including the inability to cope with the difficulties of life-have played an important role in the act of thinking about suicide. Knowing the risk factors can helpreduce suicide attempts in the at-risk group. If anincident does occur, we know thatvictims who are brought to the hospital as quickly as possible have a lower mortality rate. It should also be kept in mind that suicide attempts in women almost alwaysinvolve social messages - that is, a cry for help in dealing withdifficulties.

\section{ETHICAL APPROVAL}

The study was approved by Adiyaman University ethical committee.

\section{REFERANCES}

[1] World HealthOrganization.Suicide and SuicidePrevention in Asia. Geneva, Switzerland.2008.http://www.who.int/ mental_ health/resources/suicide_prevention_asia.pdf Date of access 24.08.2019.

[2] Durcheim E.Suicide, a study in sociology. AmericanBook-KnickerbockerPress,USA, New York, First Press; 1951. p. 44.

[3] World HealthOrganization.Suicide in theworld: globalhealthestimates. 2019 https://apps.who .int/ iris/bitstream/handle/10665/326948/WHOMSD-MER-19.3-eng.pdfDate of access 10.12. 2019

[4] Kafadar H, Kafadar, Tokdemir M.Suicides in adolescence: A twelve-yearstudy from Eastern 
Turkey.Journal of Forensic and Legal Medicine 2014;27:6-8

[5] Favazza AR, Rosenthal RJ.Diagnosticissues in self mutilation. HospCommunityPsychiatry 1993; 44:134- 140.

[6] Harmanc1 P.Examining the sociodemographic characteristics of suicidecases in theworld and Turkey. Hacettepe UniversityFaculty of Health Sciences Journal. 2015;1:1-15.

[7] Walsh BW, Rosen PM. Self-MutilationTheory, Research and Treatment. New York, Guilford, 1988.

[8] Yaylacı N, Çolak B, Ağrıtmıs H, Yavuz Imre K.Adolescentsuicidecasesthataresabmittedtoinst utite of forensicmedicine. Turk $\mathrm{J}$ MedSci 2004;1:18-24.

[9] Odağ C.Suicide (self inflected) definitiontheory-healing, Izmirpsychiatric Association PsychotherapyUnit; 1995.

[10] World HealthStatistics 2016: Monitoringhealth for theSDGs. Date of access 24.08. $2019 \mathrm{http} / /$ www.who.int/gho/publications/world_health_ statistics/2016/Annex_B/en/

[11] Prasko J, Diveky T, Grambal A, Latalova K.Suicidalpatients. Biomed PapMedFac Univ Palacky Olomouc CzechRepub. 2010:154 (3): 265-274.

[12] Arslan MM, Akçan R, Hilal A, Batuk H, Çekin N.Suicideamongchildren and adolescents: datafromCukurova, Turkey. Child Psychiatry Hum Dev 2007;38(4):271-7.

[13] Atalay IM, Eren I, Gündogar D.Suicide in Isparta provincecenter, death thought sprevalence and risk factors. J TurkPsychiatry 2012;23(2):89-98

[14] Katkıcı U, Özkök MS, Özkara E. Evaluation of suicidecases in Sivas, 1. In: Congress of forensicmedicinebooks, Adana; 1994. p. 115-8.

[15] Tüzün B, Özen S, Dokgöz H, Fincancı SK. Adolescencedeath. ForensicMedBull 1997;2 (2):67-70

[16] Agritmis H, Yaci N, Çolak B, Aksoy E.Suicidaldeaths in childhood and adolescence. ForensicSciInt 2004;142:25-31.

[17] Hekimoglu Y, Melez IE, Canturk N, Erkol ZZ, Dizdar MG, Canturk G, et al. A descriptivestudy of femalesuicidedeathsfrom 2005 to 2011 in Van city, Turkey. BMC Women's Health 2016; 16(20):1-7.

[18] Bridge JA, Goldstein TR, Brent DA. Adolescentsuicide and suicidalbehavior. J Child PsycholPsychiatry 2006;47(3/4):372-94.

[19] Nijman HLI, Da Itzenberg $M$. at all. SelfmutilatingBehaviou' of Psychiatric In patients. EurPsychiatry, 1999;14:4-10.

[20] Guze SB and Robins E.Suicide and primary affectivedisorders. $\mathrm{Br}$ J Psychiatry 1970; 117:437-438.
[21] Miles CP.Conditionspredisposingtosuicide: a review. J NervMentDis 1977; 164:231-246.

[22] Dearden KA, De La Cruz NG, Crookston BT, Novilla LB, Clark M.Adolescents at risk: depression, lowacademicperformance, violence and alcoholincreaseBolivianteenagers' risk of attemptedsuicide. Journal of HealthEducation 2005;8:104-19.

[23] Varnik P.Suicide in theworld. Int J Environ Res PublicHealth 2012; 9: 760-71.

[24] Bostwick JM, Pankratz VS.Affectivedisorders and suicide risk: a reexamination. Am J Psychiatry. 2000;157:1925-32.

[25] Bertolote JM and Fleischmann A.Suicide and psychiatricdiagnosis: a worldwideperspective. World Psychiatry. 2002;1(3):181-185.

[26] Roy A.Familyhistory of suicide. Arch Gen Psychiatry. 1983;40(9):971-974.

[27] Roy A. Distal risk factorsforsuicidalbehavior in alcoholics: Replications and newfindings. J AffectDisord. 2003;77(3):267-271.

[28] Mermi O, Kılıç F, Gürok MG, Kuloğlu M, Atmaca M.TemperamentCharacteristics of PatientsAdmittedtoHospitalDuetoSuicideAttem pt. FiratMed J 2015; 20(2): 96-100.

[29] Nock MK, Deming CA, Fullerton CS, Gilman SE, Goldenberg M, Kessler RC, McCarroll JE, et al.SuicideAmong Soldiers: A Review of Psychosocial Risk and ProtectiveFactors. Psychiatry. 2013;76(2):97-125.

[30] Mokhlesi B, Leiken JB, Murray P.Adulttoxicology in criticalcare: part I: General approach to the intoxicated patient. Chest 2003; 123: 577-92.

[31] Bucca M, Ceppi M, Pelosa P, Archellaschi M, Mussi D, Fele P. Socialvariables and suicide in thepopulation of Genoa, Italy. ComprPsychiatry 1994;35:64-69.

[32] Fombonne E.Suicidalbehaviors in vulnerableadolescents. Time trends and theircorrelates. Br J Psychiatry 1998;173:154159.

[33] Kim HS, Kim HS. Risk Factors for Suicide Attempts among Korean Adolescents. Child Psychiatry Hum Dev 2008;39:221-235.

[34] Hagaman AK, Khadka S, Wutich A, Lohani S, Kohrt BA.Suicide in Nepal: QualitativeFindingsfrom a Modified CaseSeries PsychologicalAutopsyInvestigation of Suicide Deaths Cult Med Psychiatry. 2018; 42(3):704-33.

[35] Kafadar H.Death due to stomach perforation after ingested corrosivesubstance. Case report. AU HelthSic J. 2016;2(1):219-25.

[36] Mos'Cicki EK. Epidemiology of Completed And Attempted Suicide: Toward A Framework For Prevention, ClinicalNeuroscienceResearch 2001; 1: 310-23. 
[37] Goldsmith SK, Pellmar TC,Kleinman AM, Bunney WE. Reducing Suicide A Nationa limperative, The NationalAcademiesPress. 2002 p.321-4.

[38] Moscicki Ek.Epidemiology Of Completed And Attempted Suicide: Toward A Framework For Prevention. Clinical Neuroscience Research. 2001;1:310-23.

[39] Ziyalar N, Sarıpınar A, Çalıcı C. Female Suicides in Siirt District. J For Med. 2016; 30(2):117-127.

[40] Lubin G, Glasser S, Boyko V, Barell V.Epidemiology of suicide in Israel: a nation wide population study.SocPsychiatr Epidemiol 2001;36:123-7.
[41] Sayıl I, Devrimci Ozgüven H.Suicide and suicideattempts in Ankara in 1998: result of the WHO/EURO. MulticentreStudy of Suicidal Behaviour. Crisis 2002;23:11-6.

[42] Phillips RM, Liu H, Zhang Y.Suicide and socialchange in China. CultMedPsychiatry 1999;23:25-50.

[43] Shain BN.Suicide and suicideattempts in adolescents. PhD, and the Committee on Adolescence. Pediatrics 2007;120:669-71.

[44] Chen CY, Yeh HH, Huang N, Lin YC. Socioeconomic and clinical characteristics associated with repeat suicide attempts among young people. J AdolescHealth 2013;10:1-8.

Citation: Hüseyin Kafadar, Irfan Aydın. Retrospective Analysis of Female Patients Admitted to Hospital Due to Suicide Attempts.ARC Journal of Forensic Science. 2020 5(1):13-20. http://dx.doi.org/10.20431/2456-0049. 0501003.

Copyright: (C) 2020 Authors. This is an open-access article distributed under the terms of the Creative Commons Attribution License, which permits unrestricted use, distribution, and reproduction in any medium, provided the original author and source are credited. 